\title{
REFLEXIONES SOBRE LOS MECANISMOS DE JUSTICIA PENAL NEGOCIADA EN CHILE
}

\author{
REFLECTIONS ON THE NEGOTIATED CRIMINAL JUSTICE \\ MECHANISMS IN CHILE
}

\section{Guillermo Oliver Calderón*}

RESUMEN: En este artículo, se revisan las más importantes ventajas y desventajas que se han atribuido a los mecanismos de justicia criminal negociada en sentido restringido y se analiza su aplicabilidad o inaplicabilidad al sistema chileno de justicia penal negociada.

Palabras clave: Justicia penal negociada, procedimiento abreviado, procedimiento simplificado con admisión de responsabilidad, procedimiento monitorio, renuncia al juicio oral.

ABSTRACT: In this paper, we review the most important advantages and disadvantages that have been attributed to the negotiated criminal justice mechanisms in a restricted sense and analyze its applicability or inapplicability to the Chilean system of negotiated criminal justice.

Keywords: Negotiated criminal justice, abbreviated procedure, simplified procedure with admission of liability, order for payment procedure, waiver of oral proceedings.

\section{INTRODUCCIÓN}

En un sentido amplio, con la expresión "justicia penal negociada” cabe aludir a todo acuerdo que el imputado, en un proceso penal, puede celebrar con el fiscal o con la víctima, sin que necesariamente tal acuerdo conduzca a una sentencia que condene o absuelva. En un sentido restringido, se la usa para hacer referencia solo a mecanismos de negociación penal que llevan a una sentencia definitiva de absolución o condena ${ }^{1}$. En este trabajo, dicha expresión es utilizada en un sentido restringido, sea que el acuerdo se proyecte solo sobre el rito procedimental para simplificar su tramitación, sea que recaiga también sobre el mérito fáctico o jurídico de la pretensión punitiva ${ }^{2}$.

* Doctor en Derecho por la Universidad de Barcelona. Profesor de Derecho Penal y Derecho Procesal Penal de la Pontificia Universidad Católica de Valparaíso. Dirección electrónica: guillermo.oliver@pucv.cl. Dirección postal: Avenida Brasil 2950, Valparaíso, Chile. Este trabajo se inserta en el proyecto de investigación Fondecyt $\mathrm{N}^{\circ}$ 1170949, "Formulación de una teoría general de los mecanismos de renuncia al juicio oral con base en el Derecho Procesal Penal chileno: estudio dogmático y crítico”, en el que el autor se desempeña como investigador responsable.

El autor agradece a los profesores de la Pontificia Universidad Católica de Valparaíso, Raúl Núñez Ojeda y Jaime Vera Vega, por sus valiosas observaciones y sugerencias a una versión preliminar de este texto. Agradece también al ex Fiscal Regional de Valparaíso, Pablo Gómez Niada, por su ayuda en la búsqueda de información estadística relevante para la elaboración de este trabajo.

1 Sobre los dos sentidos en que puede ser utilizada dicha expresión, véase Herrera (2014) pp. 57-69.

2 Efectúa esta distinción entre el consenso sobre el rito procedimental y el consenso sobre el mérito del proceso, Del Río (2009) pp. 21-25. 
En general, los sistemas de justicia penal negociada, cuyo origen acostumbra situarse en el modelo norteamericano ${ }^{3}$ y que han ido permeando los procesos penales de Europa continental ${ }^{4}$ y de Latinoamérica, especialmente tras varias reformas de la segunda mitad del siglo pasado 5 , se caracterizan por la celebración de acuerdos entre el imputado y el persecutor, en cuya virtud aquél renuncia a la posibilidad de intervenir en un juicio oral, a cambio de lo cual obtiene beneficios procesales o penales, todo sujeto a control judicial ${ }^{6}$.

Es común encontrar en el Derecho comparado manifestaciones de justicia penal negociada. Destaca, por ejemplo, en Estados Unidos, el conocido plea bargaining, tanto cuando la negociación recae sobre los cargos (charge bargaining), como cuando lo hace sobre la sentencia (sentence bargaining) (Federal Rules of Criminal Procedure, rule $\mathrm{N}^{\circ} 11$ ). En el ámbito del procedimiento continental europeo sobresalen, en Alemania, la Absprache ( $\$ 257$ C Strafprozeßordnung) (en adelante, StPO); en Italia, el giudizio abbreviato (pacto sobre el procedimiento, arts. 438 a 443 Codice di Procedura Penale) ${ }^{7}$ y la applicazione della pena su richiesta delle parti o patteggiamento (pacto sobre la pena, arts. 444 a 448 Codice di Procedura Penale); en España, la "conformidad del acusado" (arts. 784.3, 787.1 y 801 Ley de Enjuiciamiento Criminal) ${ }^{8}$ (en adelante, LECrim); en Portugal, el "proceso sumarísimo" (arts. 392 a 398 Código de Proceso Penal); en Francia, el "procedimiento de comparecencia con reconocimiento previo de culpabilidad" (art. 495-7 Code de Procédure Pénale). En el panorama centro y sudamericano, en Colombia, los "preacuerdos y negociaciones" (arts. 348 a 354 Código de Procedimiento Penal); en Nicaragua, el "acuerdo" (art. 61 Código Procesal Penal); en Perú, la "terminación anticipada" (arts. 468 a 471 Código Procesal Penal); en Guatemala (arts. 464 a 466 Código Procesal Penal), en Costa Rica (arts. 373 a 375 Código Procesal Penal), en Bolivia (arts. 373 y 374 Código de Procedimiento Penal) y en Argentina, el "procedimiento abreviado" (regulado, tanto en el antiguo, pero aún vigente Código Procesal Penal de la Nación, art. 431 bis, como en el aprobado y publicado, pero todavía en vacancia nuevo Código Procesal Penal de la Nación, arts. 288 y ss., además de algunos códigos provinciales, como el de Córdoba, art. 415, y el de Buenos Aires, art. 395), etc.

\footnotetext{
3 En este sentido, Del Corral (2010) p. 41. Véase, sin embargo, Nieva (2012) p. 220, quien niega que el origen de estos sistemas sea anglosajón, afirmando que en realidad provienen de la confesión del procedimiento inquisitivo.

4 En lo cual tuvo gran relevancia una recomendación del Comité de Ministros del Consejo de Europa de 1987, en el sentido de utilizar el procedimiento de reconocimiento de culpabilidad del modelo angloamericano. Cfr. Del Corral (2010) p. 50.

5 Barona (2004) pp. 189-195.

6 Por todos, Correa y Reyes (2012) pp. 17-18.

7 En todo caso, a partir de una reforma de 1999, se ha cuestionado el carácter de negociación del giudizio abbreviato italiano, porque para que este procedimiento se verifique basta con la voluntad del imputado, sin que se requiera que el Ministerio Público esté de acuerdo. Así, Del Río (2009) pp. 22-23, n. 4.

8 Véase Gimeno (2012) pp. 703-711, quien afirma que, en estricto rigor, la conformidad del acusado no es una forma de negociación, sino un acto unilateral exclusivo de la defensa (p. 705). En el mismo sentido, GARCía (2004) p. 53. No obstante, parece evidente que presenta características negociales, como lo demuestra la previsión legal de que, en ciertos casos, la conformidad deba constar en un escrito que firmen conjuntamente el acusador y el acusado (art. 784.3 LECrim). Lo reconoce ARMENTA (2014) pp. 281-282.
} 
En el Código Procesal Penal chileno (en adelante, CPP), han sido considerados como expresiones de justicia criminal negociada, tanto el procedimiento abreviado ${ }^{9}$, como el procedimiento simplificado con admisión de responsabilidad ${ }^{10}$, y también la no reclamación del imputado contra la resolución que acoge el requerimiento de procedimiento monitorio y la proposición allí contenida de imposición de una multa ${ }^{11}$.

Según mi opinión, la decisión de implementar mecanismos de justicia penal negociada en los sistemas procesales penales latinoamericanos en general, y en el chileno en particular, no fue objeto de demasiada reflexión ${ }^{12}$, muy probablemente porque fue un tanto opacada por una modificación simultánea de mucho mayor calado, que buscaba sustituir íntegramente un muy antiguo y arraigado procedimiento penal de corte inquisitivo por un nuevo sistema de carácter acusatorio y adversarial. En este sentido, la incorporación de dichos mecanismos cumplió el papel de un verdadero "caballo de Troya" del sistema adversarial $^{13}$. En el caso chileno, solo se tomó en cuenta el efecto descongestionante que se esperaba que tales mecanismos tuvieran en el sistema ${ }^{14}$.

La relativamente reciente ampliación en Chile del ámbito de aplicación de uno de dichos mecanismos, al aumentarse el límite máximo de la pena que el fiscal debe solicitar para que tenga lugar el procedimiento abreviado, cuando se trata de ciertos delitos contra la propiedad -modificación hecha por la Ley $\mathrm{N}^{\circ}$ 20.931, de julio de 2016-, constituye una buena oportunidad para (volver a) reflexionar sobre los sistemas de justicia penal negociada.

En este trabajo, se revisarán sintéticamente los más importantes defectos y virtudes que suelen atribuirse a estos mecanismos, para enseguida dedicarse a su principal objetivo: el examen de la aplicabilidad o inaplicabilidad de tales ventajas y desventajas en el sistema chileno.

\footnotetext{
9 Cfr. Maturana Montero (2017) Tomo II, pp. 1341-1343. Como paradigma de la negociación entre el Ministerio Público y el imputado lo considera Matus (2011) p. 59.

10 Matizadamente, Salas (2015) pp. 219-228.

11 López (2002) Tomo I, p. 95. Sugieren lo contrario Rodríguez y Pino (2015) p. 1004, n. 4.

12 Para el caso argentino, lo reconoce MAIER (2001) pp. II-III, aludiendo al procedimiento abreviado, al declarar lo siguiente: “Sin duda, el orgullo que sin modestia siento al observar cómo 'prendieron' ciertas instituciones de aquel Proyecto de 1986, con el tiempo, y cómo variaron los problemas y la terminología científica nacional a partir de aquel Proyecto, no se reproduce en este caso. Aquí he dado pie, sin una reflexión política y de fondo, a una institución, en principio extraña a nuestra cultura jurídica, que se expande y amenaza con derribar pilares de nuestra comprensión de la pena estatal y del procedimiento necesario para imponerla" (el destacado ha sido añadido).

13 LANGer (2010) pp. 46-50.

14 En el mensaje presidencial con que se inició la tramitación parlamentaria de la LEY N ${ }^{\circ}$ 19.696, que estableció el Código Procesal Penal, se lee lo siguiente: "El examen de los problemas del sistema vigente, así como la experiencia comparada muestran que uno de los mayores obstáculos al éxito de la justicia criminal lo constituye el manejo de volúmenes muy grandes de casos, cuyos requerimientos suelen exceder con mucho las posibilidades de respuesta de los órganos del sistema con sus siempre limitados recursos [...]. [S]e propone la creación de algunos procedimientos simplificados en que por la vía de acuerdos entre todos los intervinientes o de algunos de ellos, se supriman etapas del curso ordinario del procedimiento de modo que se permita alcanzar una solución rápida del caso por medio de una sentencia definitiva, siempre que ello resulte posible sin vulnerar los valores que el sistema busca proteger".
} 


\section{VENTAJAS Y DESVENTAJAS DE LOS SISTEMAS DE JUSTICIA PENAL NEGOCIADA}

\section{VENTAJAS}

Entre las ventajas destacadas por los partidarios de los modelos de justicia criminal negociada cabe mencionar consideraciones utilitaristas. Si se asume como premisa que es imposible para cualquier sistema procesal penal someter a juicio oral todos los casos que conoce, se arguye que sería necesario establecer mecanismos de solución negociada de los conflictos penales ${ }^{15}$. Se trata de un argumento de eficiencia en la utilización de los escasos recursos humanos y materiales con que cuenta todo sistema de enjuiciamiento criminal ${ }^{16}$.

Por lo ilustrador que resulta para dimensionar la fuerza de esta clase de consideraciones, es útil citar el caso de Alemania, país en el que el principio de legalidad (u obligatoriedad) en la persecución penal dominó sin contrapeso por mucho tiempo. Si bien hasta hace pocos años la Ordenanza Procesal Penal alemana no regulaba explícitamente mecanismos de justicia penal negociada, en la práctica forense de dicho país se impuso, aproximadamente a partir de los años ochenta y aparentemente debido a una sobrecarga del sistema judicial al que ingresaban cada vez más asuntos penales, especialmente en el ámbito económico ${ }^{17}$ -a pesar de que ya se habían introducido formas de procedimiento simplificado para hacer más eficiente el sistema ${ }^{18}$-, la denominada Absprache, un informal convenio que, sin expreso respaldo legal, permitía a las partes en el proceso penal consensuar, entre otros aspectos, el procedimiento aplicable, la extensión de la pena a imponer y su forma de cumplimiento. Mientras un sector de la doctrina de dicho país se mostraba conforme con esta práctica e incluso la consideraba legal ${ }^{19}$ (también el Bundesgerichtshof en sus sentencias de 28 de agosto de 1997 y de 10 de junio de 1998 ${ }^{20}$, otro sector la calificaba como extra legem ${ }^{21}$, y un tercero estimaba que era derechamente contraria a la ley y la rechazaba con mucha fuerza ${ }^{22}$. Una modificación de 2009 en la StPO puso fin a esta situación, reconociendo explícitamente la posibilidad de celebrar estos acuerdos y recogiendo varias de las reglas que hasta entonces había elaborado la jurisprudencia para su celebración (principalmente, $\$ 257 \mathrm{C}$ ) ${ }^{23}$. Sin embargo, recientes investigaciones empíricas sugieren que, en la práctica, las Absprachen han seguido teniendo lugar de manera libre e informal, sin ajustarse en muchos casos (más del sesenta por ciento) a las restricciones de la regulación recogida el 2009 en la StPO ${ }^{24}$.

\footnotetext{
15 Horvitz (2004) Tomo II, p. 504.

16 Riego (2000) p. 208, quien destaca el ahorro de recursos no solo por parte del sistema judicial, sino también por parte de la víctima y del imputado. Véase, asimismo, Martínez (2004) pp. 55-56.

17 RÖNNAU (1990) p. 45.

18 Turner (2016) p. 1571.

19 TscherWinka (1995) pp. 51-64.

20 Un comentario crítico de dichas sentencias, junto con una síntesis de la evolución jurisprudencial del Tribunal Supremo Federal alemán anterior a tales fallos, puede verse en CóRdoba (2001) pp. 737-755.

21 Así, Gössel (2007) p. 282.

22 SCHÜNEMANn (2002) pp. 291-301.

23 Volk (2016) p. 395.

24 Altenhain et al. (2013) pp. 36-37.
} 
Esto último llevó al Tribunal Constitucional de este país, en sentencia de 19 de marzo de 2013 en la que incluyó los resultados de esas investigaciones empíricas, a estimar contraria a la Ley Fundamental dicha práctica, aunque sin declarar inconstitucional tal regulación, y a exigir, entre otras cosas, que la confesión del imputado fuera corroborada con prueba que se rindiera en la audiencia de instrucción y juzgamiento ( $\mathrm{N}^{\circ}$ marg. 65-70), que no se renunciara a los recursos $\left(\mathrm{N}^{\circ}\right.$ marg. $\left.77-78\right)$ y que se protocolizaran los acuerdos, dejando constancia de los aspectos nucleares de la negociación ( $\mathrm{N}^{\circ}$ marg. 79-88). Según un sector de la doctrina alemana, el cumplimiento de las exigencias hechas por el Tribunal Constitucional podría en la práctica eventualmente entorpecer la celebración de dichos acuerdos ${ }^{25}$.

Adicionalmente, se ha puesto de relieve, como otra virtud de los mecanismos de justicia penal negociada, el hecho de que, gracias a ellos, se velaría por el respeto al derecho del imputado a ser juzgado dentro de un plazo razonable. En un sistema que careciera de tales mecanismos y que buscara someter a juicio oral todos los casos, el cumplimiento de ese derecho se convertiría en una quimera ${ }^{26}$.

\section{DESVENTAJAS}

Sin embargo, los sistemas de justicia criminal negociada también han recibido varias críticas $^{27}$. Tal vez la que más se ha destacado ${ }^{28}$ es su potencial carácter coactivo. El reproche que se suele formular se basa en la afirmación de que muchas veces el imputado acepta los hechos que se le atribuyen y el mecanismo alternativo al juicio oral que muy probablemente terminará con una sanción de baja intensidad, únicamente por la amenaza de que en el juicio se le podría imponer una pena mucho más grave, en lo que inciden, tanto la práctica del overcharging, esto es, el incremento artificial de los cargos en contra del imputado para forzar su aceptación ${ }^{29}$, sea que se trate de un aumento sin razón del número de imputaciones contra un mismo acusado (horizontal overcharging), o de una ampliación, también sin razón, del único cargo contra el imputado (vertical overcharging) ${ }^{30}$, como la tendencia del abogado defensor a intentar convencer al imputado de que renuncie al juicio oral para así poder recibir sus honorarios o su remuneración en el menor tiempo y con el menor esfuerzo posible ${ }^{31}$, todo lo cual puede llevar incluso a personas inocentes a admitir culpabilidad en los hechos que se les atribuyen ${ }^{32}$. De este modo, la efectiva aplicación de una pena más

25 LOCKER (2015) p. 40.

26 Horvitz (2004) Tomo II, p. 504; Durán (2009) pp. 55-57.

27 En la exposición de estas críticas se distingue entre aquellas que provienen de la doctrina procesal penal y aquellas que han sido formuladas por la doctrina penal. Esta decisión busca sistematizar mejor los distintos planteamientos, pero no pretende negar que los problemas procesales penales se proyectan necesariamente en los aspectos penales sustantivos, y viceversa.

28 Lo reconoce Nieva (2012) p. 217.

29 LIPPKe (2011) pp. 31-34.

30 Rodríguez y Pino (2015) p. 1008.

31 De Diego (1999) pp. 59-60. Véase también Alschuler (1975) p. 1182, quien alude, citando a George L. Vaughn, a los denominados "professional writ-runners and pleaders", es decir, abogados que siempre negocian y nunca llevan un caso a juicio oral.

32 Rodríguez (1997) pp. 104-106. 
severa $^{33}$ acaba siendo percibida como un verdadero castigo para quienes deciden defenderse y ejercer su derecho a un juicio oral ${ }^{34}$. Esta crítica es especialmente intensa para el plea bargaining de los Estados Unidos ${ }^{35}$, pero también es formulada con firmeza para instituciones semejantes reguladas en legislaciones de otros países ${ }^{36}$.

Otra crítica que se ha planteado contra los sistemas de justicia criminal negociada, aunque con menor intensidad que la anterior, apunta a la deficitaria verdad procesal en que se funda la solución del conflicto penal que se adopta. La doctrina acostumbra a destacar, como ventaja del juicio oral (y de las que se dice que son sus inseparables acompañantes, la inmediación y la contradictoriedad), que permite alcanzar una verdad procesal de calidad muy superior ${ }^{37}$. Incluso, hay quienes señalan que, por ello, el juicio oral posee la virtud de que contribuye mejor a "redefinir" el conflicto penal en términos pacíficos y "reinstalarlo" en la sociedad ${ }^{38}$. Pues bien, un sector doctrinal señala que cuando se aplican mecanismos de justicia penal negociada, se produce un inaceptable abandono del fin del proceso penal consistente en la averiguación de la verdad ${ }^{39}$, lo que a su vez se traduce en un déficit de legitimidad de la sanción penal consensuada. En palabras de Schünemann, "el juicio oral corporiza, por su estructura contradictoria, recursos para hallar la verdad, que desaparecen en un procedimiento regido por acuerdos. Como es sabido, en la instrucción se refleja una imagen selectiva del hecho, constituida esencialmente por la actividad instructoria de la policía y según determinadas hipótesis de sospecha. Estas no pueden conducir a la determinación de la verdad material sin una verificación crítica a la luz de los hechos que presenta el acusado, visión que suele aparecer precisamente en el juicio oral” ${ }^{\prime 0}$.

En otro orden de ideas, los mecanismos de solución negociada del conflicto penal han recibido críticas, también menos vigorosas que aquellas que reprochan su carácter coactivo, pero desde la doctrina penal, que ponen de relieve la incidencia que dichos mecanismos tendrían en una merma de la eficacia preventiva de la pena y de la función protectora de bienes jurídicos del derecho penal. Si para desplegar su efecto preventivo general y especial es necesaria una determinada intensidad de la reacción punitiva, inevitablemente dicho efecto preventivo se deteriora al aplicar una pena de menor entidad como consecuencia de la utilización de tales mecanismos ${ }^{41}$.

\footnotetext{
33 Severidad que, en el sistema norteamericano, ha sido calculada, por algunos, en un alza de treinta a cuarenta por ciento de las penas que suelen imponerse en los mecanismos de justicia negociada (cfr. WILKINS (1988) p. 191), y por otros, en un aumento de cuarenta a cincuenta por ciento (GARCía (2004) pp. 84-85).

34 PizZi (1999) pp. 189-192.

35 Paradigmáticamente, LANGbein (1978) pp. 3-22.

36 Para el caso italiano, véase Ferrajoli (2000) pp. 746-752.

37 Así, entre otros, Palomo (2010) p. 148; Duce et al. (2008) pp. 46-65; Andrés (2003) p. 57; con especial elocuencia, Baytelman (2000) p. 243. Véase también Baytelman y Duce (2004) pp. 151-152. En todo caso, un sector doctrinal, junto con reconocer las virtudes de la oralidad, manifiesta la necesidad de no "sacralizarla" ni de "demonizar" la escrituración. En este sentido, NieVA (2010) pp. 237-257.

38 En este sentido, Binder (2004) pp. 103-105.

39 Así lo sugiere Cociña (2012) pp. 69-72.

40 Schünemann (2002) p. 299.

41 Véase Herrera (2014) pp. 229-281; Herrera (2016) pp. 229-263. Asimismo, Núñez (2014) p. 393.
} 
Asimismo, se han criticado los sistemas de justicia penal negociada por la vulneración que en su aplicación se puede producir para el principio de igualdad. La base de esta crítica se encuentra en la discrecionalidad del fiscal para decidir negociar con un imputado y no con otro, a pesar de que ambos puedan hallarse en la misma situación, sin que existan motivos para un tratamiento diferenciado ${ }^{42}$.

\section{APLICABILIDAD O INAPLICABILIDAD DE LOS DEFECTOSY VIRTUDES DE LOS SISTEMAS DE JUSTICIA PENAL NEGOCIADA EN LA REGULACIÓN CHILENA}

Un sector reducido de la doctrina nacional, especialmente en los albores de la Reforma Procesal Penal del año 2000, manifestó sus temores de que las críticas formuladas por la doctrina extranjera contra los sistemas de justicia penal negociada, en general, y contra el plea bargaining norteamericano, en particular, resultaran también aplicables a los mecanismos de negociación penal que se incorporarían en el nuevo modelo procesal penal chileno ${ }^{43}$.

Transcurridos ya casi veinte años desde la modificación del proceso penal en el país, no parece que sea posible efectuar una única valoración crítica de los mecanismos de justicia penal negociada. En cuanto a las ventajas que se les atribuyen, algunas de ellas han podido ser apreciadas en la práctica; otras no, al menos, no respecto de todos los mecanismos. Del mismo modo, en relación con las críticas que se les imputan, algunas de ellas podrían ser reconocidas en la operatividad del sistema; otras no.

\section{CONSIDERACIONES DE EFICIENCIA}

Por lo que respecta a las consideraciones de eficiencia en la utilización de los recursos con que cuenta el sistema procesal penal, para valorar su incidencia en los mecanismos chilenos de justicia penal negociada es necesario efectuar una distinción. Tratándose del procedimiento abreviado, un examen hecho solo tres años después de la entrada en vigencia del sistema demostró que su aplicación tuvo lugar en un número de casos mucho menor que el esperado, por lo que su contribución a la eficiencia del proceso no fue especialmente significativa. Probablemente influyó en ello el hecho de que el límite máximo de pena privativa de libertad que debe pedirse para que tenga lugar este procedimiento, estaba (y sigue, en general) fijado en cinco años de presidio o reclusión menores en su grado máximo (art. 406 $\mathrm{CPP}$ ), en circunstancias de que para varios delitos de comisión frecuente el Código Penal (en adelante, CP) prevé penas más altas ${ }^{44}$.

Pocos años después, tal vez debido a que a partir de la Ley $\mathrm{N}^{\circ} 20.074$, de 14 de noviembre de 2005, dejó de ser necesario esperar hasta la audiencia de preparación del juicio oral para que tuviera lugar el procedimiento abreviado, pudiendo promoverse desde la for-

42 Cfr. Rodríguez (1997) pp. 96-97.

43 Así, Libedinsky (2001) p. 149.

44 Véase RitTer (2003) p. 67: "La aplicación del procedimiento abreviado está limitada a una pena posible de hasta cinco años, lo que en atención a las penas draconianas previstas en el anticuado CP chileno para algunos delitos, no ocurre con tanta frecuencia como se podría esperar. Por ejemplo, este tipo de procedimiento puede no resultar aplicable en casos de delitos masivos, como es el robo con fuerza cometido en una casa habitación". 
Oliver Calderón, Guillermo — "Reflexiones sobre los mecanismos de justicia penal negociada en Chile"

malización de la investigación ${ }^{45}$, se observó un aumento en su aplicación, alcanzando un porcentaje de entre 16 y 17 \% del total de las causas terminadas por sentencia condenatoria o absolutoria ${ }^{46}$.

Desde entonces, al parecer, el procedimiento abreviado ha mantenido una tasa relativamente estable de aplicación. No resulta posible saberlo con certeza, porque lamentablemente, con posterioridad al año 2008, los boletines estadísticos anuales del Ministerio Público no desagregan la información de las sentencias definitivas, se distinguen según el tipo de procedimiento en que se dictan. Pero es altamente probable que así haya ocurrido en los años inmediatamente siguientes al 2008, ya que en la actualidad el procedimiento abreviado se ocupa en alrededor del $16 \%$ de los casos que finalizan con sentencia definitiva, como se desprende de la siguiente tabla, correspondiente a los tipos de procedimiento que terminaron con sentencias definitivas el año 2017.

\section{TABLA 1}

Número y porcentajes de casos terminados en el país por sentencia definitiva, según tipo de procedimiento, en el año $2017^{47}$

\begin{tabular}{|c|rc|}
\hline Procedimiento & Total \\
\hline Abreviado & 35.817 & $(16,34 \%)$ \\
\hline Simplificado & 96.706 & $(44,13 \%)$ \\
\hline Monitorio & 75.527 & $(34,47 \%)$ \\
\hline Juicio Oral & 11.049 & $(5,04 \%)$ \\
\hline Total & 219.099 & $(100 \%)$ \\
\hline
\end{tabular}

La tasa de aplicación del procedimiento abreviado (16,34 \%) se encuentra bastante lejos de las elevadas tasas de utilización de otros mecanismos de justicia penal negociada similares en el derecho comparado, como el plea bargaining norteamericano, el que se aplica en alrededor del $95 \%$ de las condenas ${ }^{48}$, o el procedimiento abreviado de la provincia argentina de Córdoba, cuya aplicación parece observarse en torno al $70 \%$ de las condenas ${ }^{49}$. No obstante, nunca podría nuestro procedimiento abreviado aplicarse en un número tan

\footnotetext{
45 Medida que había propuesto un sector de la doctrina para aumentar la tasa de aplicación del procedimiento abreviado. Cfr. Pecchi y Ortiz (2003) p. 58.

${ }^{46}$ Lo constata para los años 2006 a 2008, a partir de boletines estadísticos anuales del Ministerio Público, DUCE (2011) p. 57.

47 Esta tabla es de elaboración propia. La información sobre cantidad de juicios orales ha sido extraída del Boletín Anual Estadístico 2017 del Ministerio Público, disponible en el sitio web de dicha institución, y la información sobre procedimientos abreviado, simplificado y monitorio ha sido obtenida gracias a gestiones de la Fiscalía Regional del Ministerio Público de Valparaíso.

${ }^{48}$ Cfr. Mallord (2014) p. 688. Entre un 90 y un $95 \%$ lo sitúa Devers (2011) pp. 1 y 3 . En un $90 \%$ lo hace AlsChULER (1979) p. 1.

${ }^{49}$ Lo sugiere MAier (2001) p. II, aunque no sobre la base de estadísticas. En cambio, Bovino (2001) pp. 7475, alude a una estadística para el año 1995, en la ciudad de Córdoba, "según la cual el 46,2 \% de los casos se resolvieron sin juicio, es decir, a través del 'juicio abreviado"'. Por su parte, en la ciudad de Buenos Aires, el procedimiento abreviado, en el año 2007, se aplicó en el $46 \%$ de las causas que ingresaron al sistema. Cfr. DeL Corral (2010) p. IX.
} 
elevado de casos, por la menor incidencia del principio de oportunidad en el sistema chileno que en el estadounidense ${ }^{50}$ y que en el cordobés, y por sus consecuentemente mayores requisitos legales de procedencia.

El procedimiento monitorio, en cambio, ha tenido una aplicación mucho mayor que el abreviado, por lo que ha sido evidente su contribución a la eficiencia del sistema. Entre los años 2006 y 2008 la tasa de su aplicación fluctuó entre el 37 y el 41 \% del total de casos finalizados con sentencia definitiva. Así puede colegirse de los boletines estadísticos anuales del Ministerio Público correspondientes a esos años ${ }^{51}$. Lamentablemente, por las razones señaladas, no puede medirse en los boletines estadísticos del Ministerio Público de los años inmediatamente siguientes al 2008, la incidencia que el procedimiento monitorio ha seguido teniendo en la eficiencia del sistema, aun cuando no se advierten motivos para suponer que haya variado. Sin embargo, como se desprende de la Tabla 1, en el año 2017 se detecta una leve baja en su tasa de aplicación (34,47 \% de las causas terminadas por sentencia definitiva), descenso que, no obstante, en un análisis global de los mecanismos de justicia penal negociada, no parece especialmente significativo, como se explica más abajo.

Por su parte, el procedimiento simplificado también ha introducido eficiencia en el sistema, pues se ha aplicado en un número de casos similar o superior al del procedimiento monitorio. Entre los años 2006 y 2008, la tasa de su utilización fluctuó entre el 38 y el 41 $\%$ de las causas que terminaron con sentencia definitiva ${ }^{52}$. Y de la Tabla 1 se desprende un sensible aumento en su tasa de aplicación (44,13\% de las causas finalizadas con sentencia definitiva). Sin embargo, no es posible extraer de los mencionados boletines estadísticos información que permita mensurar su incidencia en cuanto mecanismo de justicia penal negociada, ya que en los correspondientes a esos años no se distingue entre sentencias dictadas en procedimiento simplificado con admisión de responsabilidad y sentencias pronunciadas sin dicha admisión; y en los boletines de los años siguientes, como se ha dicho, ni siquiera se distingue el tipo de procedimiento en que se dictan las sentencias definitivas. Pero de antiguos boletines estadísticos de la Defensoría Penal Pública puede colegirse que el porcentaje de sentencias inmediatas dictadas tras la admisión de responsabilidad es muy superior al de sentencias pronunciadas en el juicio oral del procedimiento simplificado, sin que se adviertan motivos para pensar que en la actualidad la situación sea distinta ${ }^{53}$.

En síntesis, en un análisis diferenciado para cada mecanismo de justicia penal negociada, cabría efectuar valoraciones críticas distintas, según corresponda. Tratándose del procedimiento abreviado, su incidencia en la eficiencia del sistema no ha sido especialmente

\footnotetext{
50 Así, Correa (2017) p. 27.

51 DuCE (2011) p. 57.

52 Duce (2011) p. 57.

53 Del informe estadístico del año 2006 de la Defensoría Penal Pública, que se puede consultar en su página web, se desprende que sobre un total de 40.151 causas terminadas por sentencia definitiva ese año, que se sometieron al procedimiento simplificado y que fueron asumidas por dicho servicio público, en 38.443 casos, que corresponden al 95,74\%, el imputado admitió responsabilidad; en los 1.708 casos restantes, correspondientes al 4,26 \%, no lo hizo y tuvo lugar un juicio oral simplificado. Una cifra cercana de admisión de responsabilidad en el procedimiento simplificado (93,7 \%) muestran las estadísticas recogidas en la Cuenta del Defensor Nacional de 2004, según lo indica Durán (2009) p. 159, n. 281. Esta clase de información dejó de ser incluida en las estadísticas de este servicio público correspondientes a los años posteriores.
} 
significativa, a diferencia del procedimiento monitorio. El procedimiento simplificado, por su parte, ha tenido un efecto importante en el acortamiento de trámites procesales, dada su elevada tasa de utilización, aunque no ha sido posible dimensionar con certeza su actual importancia como mecanismo de justicia negociada. Sin embargo, un análisis global de estos mecanismos sí permite realizar una valoración positiva desde el punto de vista de su contribución a la eficiencia del sistema, ya que incluso sin considerar el procedimiento simplificado, los otros dos mecanismos (procedimientos abreviado y monitorio) cubren más de la mitad de las causas finalizadas con sentencia definitiva. Si a esa suma pudiera añadirse la cifra correspondiente a los casos de admisión de responsabilidad en procedimiento simplificado, casos que aparentemente superan con largueza a los de juicio oral simplificado, se obtendría un resultado todavía más abultado y se reforzaría el carácter positivo de esta valoración.

\section{INCIDENCIA EN EL JUZGAMIENTO EN UN PLAZO RAZONABLE}

En cuanto a la incidencia de los mecanismos de justicia penal negociada en el respeto al derecho del imputado a ser juzgado en un plazo razonable, una forma de intentar medirla es examinar el tiempo promedio de duración de las causas penales. La siguiente tabla da cuenta de esta información, correspondiente al año 2017.

\section{TABLA 2}

Tiempo promedio de duración de tramitación de causas, expresado en días, en el año $2017^{54}$

\begin{tabular}{|c|c|c|}
\hline Salidas judiciales & Salidas no judiciales & Promedio salidas \\
\hline 310 & 122 & 216 \\
\hline
\end{tabular}

Lamentablemente no ha sido posible determinar, dentro de las salidas judiciales, el tiempo promedio de duración de las causas que se someten a cada uno de los mecanismos de justicia penal negociada, ya que la fuente utilizada para elaborar esta tabla no proporciona esta información. Sin embargo, sí menciona tal fuente el tiempo promedio de duración de las causas que terminan con sentencia definitiva en el juicio oral del procedimiento ordinario: 503 días. La diferencia entre esta última cifra y la que corresponde en general a las salidas judiciales (310 días), en la que un papel importante cumplen las causas que finalizan con sentencia definitiva en el procedimiento monitorio, en el procedimiento simplificado con admisión de responsabilidad y en el procedimiento abreviado, permite intuir una incidencia real de estos mecanismos en el respeto del derecho del imputado a ser juzgado dentro de un plazo razonable. En general, si una causa no se sometiera a alguno de estos mecanismos y se sujetara al juicio oral del procedimiento ordinario, muy probablemente su tiempo de duración se incrementaría en forma considerable.

\footnotetext{
54 Esta tabla es de elaboración propia. Ha sido confeccionada sobre la base de información extraída del Boletín Anual Estadístico 2017 del Ministerio Público. Las salidas judiciales comprenden las sentencias definitivas condenatorias y absolutorias, los sobreseimientos definitivos y temporales, las suspensiones condicionales del procedimiento, los acuerdos reparatorios y las facultades de no inicio. Las salidas no judiciales incluyen los archivos provisionales, las decisiones de no perseverar y los principios de oportunidad.
} 


\section{CARÁCTER POTENCIALMENTE COACTIVO}

En relación con el carácter potencialmente coactivo de estos mecanismos, en el caso del procedimiento abreviado, la sola exigencia de que para que tenga lugar sea necesario que el imputado acepte expresamente los hechos de la acusación (art. 406 inc. $2^{\circ} \mathrm{CPP}$ ), ya demuestra un evidente riesgo para el derecho de este a no ser obligado a declarar contra sí mismo ni a confesarse culpable ${ }^{55}$, derecho reconocido tanto en el artículo 14.3 letra g) del Pacto Internacional de Derechos Civiles y Políticos, como en el artículo 8.2 letra g) de la Convención Americana sobre Derechos Humanos.

En todo caso, para mantener a raya este peligro, junto con establecer el deber del juez de asegurarse de que el consentimiento del imputado se prestara voluntariamente (art. 409 CPP), a diferencia de algunos modelos que se observan en derecho comparado ${ }^{56}$, se decidió no fijar rebajas automáticas de pena. De ese modo, al asegurarse que no existiera una diferencia muy grande entre la pena imponible tras la negociación y la eventualmente aplicable en un juicio oral, se cautelaba la libertad en la decisión del justiciable ${ }^{57}$. Sin embargo, a poco andar la Reforma, el año en que comenzó a ser aplicada en la región más poblada del país (Región Metropolitana), se consagró en el artículo 407 CPP la posibilidad del fiscal de considerar la aceptación de los hechos de la acusación por parte del imputado, como suficiente para estimar concurrente la circunstancia atenuante del artículo $11 \mathrm{~N}^{\circ} 9$ CP (Ley $\mathrm{N}^{\circ}$ 20.074). Con independencia de que en la práctica se ha discutido si basta esta aceptación para la configuración de la atenuante o si se trata de una facultad enteramente discrecional del fiscal ${ }^{58}$, lo relevante para los efectos de ponderar la libertad en la decisión del acusado de someterse a este procedimiento, es que pasó a ser posible una diferencia mayor entre la pena imponible en este y la aplicable en juicio oral ${ }^{59}$.

55 En este sentido, en alusión al procedimiento abreviado de algunos Códigos de provincias argentinas, véase Del Corral (2010) p. 128: "puede sostenerse que la mera existencia de la norma legal en los códigos procesales, exigiendo la admisión de culpabilidad para quien quiera acogerse al procedimiento abreviado, impregna de aquella prohibida coactividad a todo el sistema de enjuiciamiento”. Asimismo, Villar (1997) pp. 205-206.

56 Por ejemplo, en Italia, la regulación del giudizio abbreviato prevé la reducción de la mitad de la pena en los casos de contravenciones, y de un tercio de ella cuando se trata de delitos. Además, contempla la sustitución de la pena de cadena perpetua por la de reclusión por treinta años (art. 442.2 Codice di Procedura Penale). Y en el caso de la applicazione della pena su richiesta delle parti o patteggiamento, se prevé la reducción de la pena en un tercio (art. 444.1 Codice di Procedura Penale). Otro tanto acaece en España, para cuya "conformidad del acusado", cuando tiene lugar ante el Juzgado de guardia en el "procedimiento para el enjuiciamiento rápido de determinados delitos", se prevé la reducción de la pena privativa de libertad solicitada en un tercio y se exige ciertos requisitos adicionales (art. 801 LECrim). Lo mismo se observa en Costa Rica, en cuyo "procedimiento abreviado" se contempla la posibilidad de disminuir hasta en un tercio la pena mínima prevista para el correspondiente tipo penal (art. 374 inc. $2^{\circ}$ Código Procesal Penal).

57 Entre nosotros, destaca esta incidencia de la cuantía de la rebaja de la pena en la voluntariedad y libertad de la renuncia al juicio oral, Del Río (2009) pp. 196-197. En Alemania, acepta una rebaja pequeña de la pena en la Absprache, pero se opone a una disminución muy grande, entre otras razones, porque, "en caso de una realización del juicio oral, el enorme aumento de pena que amenazaría como espada de Damocles, destruiría toda voluntariedad en la decisión del inculpado", SCHÜNEMANn (2005) pp. 107-108.

58 Véanse ambas posiciones jurisprudenciales en SALAS (2015) pp. 264-267. Aprecian en esto una facultad que depende solo de la decisión del fiscal, GuZmán (2008) p. 14; CHAHuán (2012) p. 324.

59 Diferencia que, sin embargo, Rodríguez (2011) p. 502, califica como "mezquina recompensa para el acusado que renuncia al juicio oral”. 
El camino iniciado el año 2005 se profundizó para el juzgamiento de ciertos delitos el 2016 con la Ley $\mathrm{N}^{\circ}$ 20.931, de 5 de julio. Esta ley, cuando se trata, en general, de delitos de hurto, robo, abigeato y receptación, delitos que, como es sabido, ocupan un lugar muy importante en las tasas nacionales de criminalidad ${ }^{60}$, estableció la facultad del fiscal o el querellante, según el caso, de solicitar una pena inferior en un grado al mínimo de los señalados por la ley (art. 407 inc. cuarto CPP). Varios de esos delitos tienen penas de crimen, en las que, como también es conocido, la rebaja de un grado se traduce en cinco años menos de cárcel ${ }^{61}$. Como puede advertirse, al menos tratándose de estos delitos, se ha incrementado considerablemente la diferencia entre la pena susceptible de imponerse en el procedimiento abreviado y la eventualmente aplicable en el juicio oral, con la consiguiente crítica de merma en la libertad de decisión del imputado, quien bien podría estar en prisión preventiva, sujeto a condiciones de hacinamiento y sobrepoblación ${ }^{62}$, y estimar la renuncia a su derecho al juicio oral como la única forma de recuperar rápidamente su libertad ambulatoria ${ }^{63}$. En estas circunstancias, incluso no es descartable que quien se someta a un procedimiento abreviado y a la muy probable pena, en verdad, sea inocente ${ }^{64}$.

Es de esperar que no se profundice este camino ${ }^{65}$ y que no se siga el ejemplo de otras legislaciones, como, por ejemplo, la colombiana (arts. 351 inc. $1^{\circ}, 352$ in. $2^{\circ}$ y 367 inc. $2^{\circ}$ Código de Procedimiento Penal), en las que se establecen incentivos penológicos más intensos para el imputado, ofreciéndole rebajas de pena mayores si renuncia al juicio casi inmediatamente después de conocido el hecho delictivo, que si lo hace en un momento posterior del proceso. La razón de la objeción está en la velada coacción que se emplea en su contra para que no produzca prueba de descargo, porque hacerlo le privaría del beneficio penológico más intenso ${ }^{66}$.

${ }^{60}$ Conforme al Boletín Anual Estadístico 2017 del Ministerio Público, de un total de 1.323.324 causas ingresadas al sistema penal en el año 2017, 549.999 causas, es decir, el 41,56 \%, correspondieron a las categorías de "hurtos" (hurto simple, hurto agravado, hurto de bienes pertenecientes a redes de suministro público y hurto de hallazgo), "otros delitos contra la propiedad” (básicamente, extorsión, abigeato, receptación, usurpación, incendio, estragos y daños), "robos" (robo simple, robo calificado y robo por sorpresa) y "robos no violentos" (robos con fuerza en las cosas).

${ }^{61}$ La posibilidad de que el procedimiento abreviado tenga lugar cuando se trata de (ciertos) crímenes, que también fue incorporada por la citada LEY $N^{\circ} 20.931$, es examinada críticamente más abajo.

${ }^{62}$ Véase el informe del Subcomité para la Prevención de la Tortura y Otros Tratos o Penas Crueles, Inhumanos o Degradantes, de 27 de junio de 2016, relativo a la visita efectuada a Chile entre el 4 y el 13 de abril de 2016, en el que se da cuenta de condiciones de hacinamiento y sobrepoblación en algunos penales visitados, además de ciertas presiones denunciadas por internos, todo lo cual configura, a juicio del Subcomité, "incentivos" injustificados para someterse a procedimientos penales auto-incriminatorios (párrafos 29 a 31).

${ }^{63}$ Destaca la incidencia de la prisión preventiva en la falta de libertad del imputado que decide renunciar a su derecho a un juicio oral y público, RIEGO (2001) pp. 474-475.

${ }^{64}$ Lo reconoce Duce (2013) p. 111.

65 Véase Riego (2017) p. 1103, quien destaca lo peligroso de la senda iniciada con la LeY $\mathrm{N}^{\circ} 20.931$, por el riesgo de alejamiento del debido proceso a favor de una adjudicación unilateral del fiscal de penas coercitivamente impuestas en acuerdos que en realidad no son tales, y por la segmentación del sistema de justicia penal en dos subsistemas: uno para la delincuencia callejera, con menos garantías, y otro para la delincuencia de los sectores sociales más acomodados, con mayores garantías.

66 Así, Del Corral (2010) p. 8. 
En principio, un planteamiento similar cabría efectuar respecto del procedimiento simplificado, en el que se debe preguntar al imputado si admite responsabilidad en los hechos del requerimiento, por lo que el riesgo para que se vea afectado su derecho a no ser obligado a declarar contra sí mismo ni a confesarse culpable es evidente. En la práctica, en muchas ocasiones, se ha estimado concurrente, por la sola admisión de responsabilidad, la circunstancia atenuante de responsabilidad penal del artículo 11 No 9 CP, aplicando analógicamente, in bonam partem, lo dispuesto en el artículo 407 inciso $3^{\circ}$ para el procedimiento abreviado ${ }^{67}$. Además, la citada Ley $\mathrm{N}^{\circ} 20.931$ reconoció la facultad del fiscal, en general, tratándose de delitos de hurto, robo, abigeato o receptación, de solicitar una pena inferior en un grado al mínimo de los señalados en la ley, como una forma de incentivar la admisión de responsabilidad del imputado (art. 395 inc. $2^{\circ} \mathrm{CPP}$ ). También aquí existe, entonces, una diferencia entre la pena aplicable si se admite responsabilidad y la eventualmente imponible en el juicio oral simplificado, con el consecuente riesgo para la libertad y voluntariedad de la decisión de renunciar al juicio.

Sin embargo, dado que el procedimiento simplificado se aplica a faltas y a simples delitos para los cuales el Ministerio Público requiere una pena no superior a presidio o reclusión menores en su grado mínimo (art. 388 CPP), la diferencia entre la pena imponible si se admite responsabilidad tras la rebaja en un grado y la eventualmente aplicable en el juicio, no es muy grande: en el ámbito de las faltas, tal rebaja se traduce solo en veinte días menos de cárcel, y en el de los simples delitos, en cuatrocientos ochenta días menos. Esto permite moderar mucho la crítica y sostener que la rebaja de pena se mantiene dentro de lo razonable para hacer atractiva para el imputado la renuncia al juicio, sin un exagerado riesgo de merma en la libertad de decisión del imputado ${ }^{68}$, incluso si se extendiera a otros delitos aquella facultad de disminución de la pena ${ }^{69}$.

En el procedimiento monitorio, el hecho de que la pena que se arriesga sea de multa y que su cuantía, por tratarse de una falta, sea baja - no más de cuatro unidades tributarias mensuales (art. 25 inc. sexto CP)-, hace que la rebaja de un $25 \%$ de su monto, que tiene lugar si se paga la multa dentro de los quince días siguientes a la notificación al imputado, también pueda ser considerada razonable y no atentatoria contra su libertad de decisión de renunciar al juicio.

\section{DEFICITARIA VERDAD PROCESAL}

En relación con la crítica relativa a la deficitaria verdad procesal en que se funda la decisión judicial cuando se aplican los mecanismos de justicia penal negociada, la circunstancia de que en estos casos no se rinde prueba en una audiencia de juicio conduce inevita-

67 En este sentido, entre muchas otras sentencias, puede verse CONTRA O.G.S.M. (2015).

68 Esto es así no solo cuando, como ocurre por regla general, los mencionados delitos están sancionados con penas privativas de libertad, sino también y con mayor razón cuando excepcionalmente lo están con penas restrictivas de libertad o privativas de otros derechos.

69 Como lo propone, de modo general, Hidalgo (2004) p. 20. 
blemente a reconocer su validez ${ }^{70}$. Ni en el procedimiento abreviado ${ }^{71}$, ni en el monitorio, ni tampoco cuando el imputado admite responsabilidad en el procedimiento simplificado, la sentencia se apoya en prueba alguna, sino solo en antecedentes de la investigación, lo que resalta su carácter contra epistemológico ${ }^{72}$.

Esta crítica apunta al núcleo de aquellos mecanismos, ya que atendida la renuncia al juicio oral que suponen, no resulta posible fundar la sentencia en una verdad procesal de calidad superior ${ }^{73}$. En otras palabras, quien quiera implementarlos en un sistema procesal penal, debe estar dispuesto a aceptar dicho déficit como un costo; a la inversa, quien solo desee sentencias definitivas fundadas en la mejor verdad procesal posible de alcanzar, no puede tolerar la incorporación de estos mecanismos.

Como se ha explicado más arriba, un análisis global de tales mecanismos merece una valoración positiva desde el punto de vista del funcionamiento eficiente del sistema procesal penal chileno, sin que parezca razonable proponer su supresión. Por ello, las consideraciones críticas sobre la verdad procesal en que se basan las sentencias en el procedimiento abreviado, en el procedimiento simplificado con admisión de responsabilidad y en el procedimiento monitorio, deberían matizarse a partir de la mayor o menor gravedad del delito perseguido y de la mayor o menor entidad de las penas posibles de imponer en cada caso. Así, al tratarse del procedimiento monitorio, la deficiente verdad procesal en que se funda la sentencia que acoge el requerimiento e impone la sanción solicitada por el fiscal, podría ser estimada como tolerable en atención a la mínima gravedad del delito por el que se sanciona (falta), a la naturaleza de la pena que se impone (multa) y a su exiguo monto (no más de cuatro unidades tributarias mensuales), monto que es rebajado si la multa es pagada dentro de quince días. Por estas razones, no parece que la deficiente verdad procesal

\footnotetext{
70 Por algo se ha dicho, con razón, que "la negociación ha florecido especialmente en aquellos sistemas en que el proceso penal se concibe como un ámbito de solución de conflictos, y no de búsqueda de la verdad material”. Horvitz (1994) pp. 27-28.

71 Muy claramente destaca la falta de idoneidad del procedimiento abreviado para descubrir la verdad, HoRVITZ (2016): "El procedimiento abreviado carece por completo de las características de un procedimiento cognoscitivo, pues asigna validez a actos realizados fuera del contradictorio en base a un acuerdo o negociación entre fiscal e imputado (y eventualmente la víctima), limitándose el tribunal a efectuar un control formal de los antecedentes de la investigación quien emite su decisión en base al debate habido en la audiencia respectiva y las solicitudes de las partes, sin rendición de prueba alguna y, por lo mismo, sin motivar su fallo en los términos del artículo 297 del Código Procesal Penal" (p. 64). "El procedimiento abreviado no busca establecer la verdad de los hechos o, al menos, no es su propósito principal. Su razón de ser es, más bien, instrumental: obtención de sentencias (condenas) rápidas, descongestión y ahorro de recursos” (p. 67). Similar, Cerda (2010) Tomo II, p. 706.

72 Destaca la naturaleza contra epistemológica de los mecanismos de justicia penal negociada GASCÓN (1999) p. 127. También Del Río (2010) p. 361.

73 Reconoce la menor calidad de la verdad en que se funda la decisión cuando se adoptan estos acuerdos en el proceso penal, Silva (2015) pp. 284-285, quien, con la finalidad de sustraerlos de la dinámica de la coacción y el temor, propone concebirlos como "escenarios de debate sobre el Derecho aplicable en marcos de incertidumbre fáctica. En escenarios así, en lugar de la verdad material -con matices- resultante de la valoración judicial de la prueba, que dibuja un relato fáctico único, aparecen varias narraciones alternativas más o menos probables. Al debate sobre el Derecho aplicable habría que anteponerle, pues, otro sobre la mayor o menor probabilidad de las narraciones enfrentadas". También lo reconoce, en referencia al procedimiento abreviado del Código Procesal Penal de la Nación de Argentina (art. 431 bis), Marino (2001) p. 25. Asimismo, GUZMÁn (2001) pp. 277-298.
} 
alcanzada se traduzca en un déficit de legitimidad de la sanción penal. Algo similar ocurre en el procedimiento simplificado con admisión de responsabilidad. La baja gravedad de los delitos a los que se aplica este procedimiento (faltas o simples delitos por los cuales el fiscal pide una pena no superior a quinientos cuarenta días de presidio o reclusión menores en su grado mínimo), también permite tolerar la deficiente verdad procesal en que se funda la sentencia, sin que parezca ilegítima la sanción penal que eventualmente se imponga.

Sin embargo, en el caso del procedimiento abreviado el análisis conduce a una valoración distinta. Si bien este procedimiento, en general, es aplicable solo a simples delitos, el hecho de que la pena solicitada por el fiscal en su acusación pueda llegar hasta los cinco años de presidio o reclusión menores en su grado máximo, permite poner en duda la tolerabilidad de la deficiente verdad procesal en que se funda la sentencia y, consecuentemente, cuestionar la legitimidad de la sanción que se imponga. Eventualmente, puede contribuir a superar la crítica, la consideración de que cinco años es justamente el límite máximo de pena privativa (o restrictiva) de libertad a que debe ser condenada una persona para poder reemplazar la sanción por una de las penas sustitutivas contempladas en la Ley $\mathrm{N}^{\circ}$ 18.216, por lo que, si se cumplen los demás requisitos legales, el condenado en procedimiento abreviado no es enviado a la cárcel. Desde este punto de vista, podría apreciarse cierta coherencia intra sistemática que compense el mencionado déficit, pero debe reconocerse que en la práctica se observan varios casos de condenas en procedimiento abreviado que, por no concurrir todos los requisitos para sustituir la pena, se traducen en un cumplimiento efectivo de la sanción original ${ }^{74}$.

Por lo que se acaba de decir, resulta francamente inaceptable el hecho de que la citada Ley $\mathrm{N}^{\circ} 20.931$ haya aumentado a diez años de presidio o reclusión mayores en su grado mínimo el límite máximo de pena que el fiscal debe solicitar en su acusación para que tenga lugar este procedimiento, cuando se trata, en general, de delitos de hurto, robo, abigeato o receptación. Con un umbral de pena tan elevado, que supera largamente los límites máximos que para procedimientos similares se observan en el derecho comparado europeo continental ${ }^{75}$, y no rindiéndose prueba alguna en una audiencia de juicio oral, la sentencia que se dicta adolece de falta de legitimidad, tanto si impone la sanción, por cuya cuantía la efectiva privación de libertad es inevitable, como si absuelve al acusado ${ }^{76}$, atendida la gravedad del hecho imputado. Como puede advertirse, en estos casos, la deficiente verdad procesal en que se funda la decisión se muestra intolerable. Esta intolerabilidad se incrementa al constatar que, tras la modificación hecha por la ya citada Ley $\mathrm{N}^{\circ} 20.074$, no es necesario esperar hasta la audiencia de preparación del juicio oral para que tenga lugar

\footnotetext{
74 Véase Arellano (2017) p. 312, con estadísticas que indican que entre los años 2006 y 2015, un poco más de la mitad de las condenas dictadas en procedimientos abreviados se tradujo en penas de cárcel de cumplimiento efectivo. La tasa fluctúa entre el 54,00 \% y el 60,92\%.

75 Por ejemplo, en Italia, el patteggiamento procede respecto de delitos sancionados con una pena privativa de libertad de hasta dos años. Por su parte, en España, la "conformidad" cabe respecto de delitos castigados con no más de seis años de privación de libertad.

76 No puedo examinar aquí la discusión sobre si es posible en el procedimiento abreviado absolver al imputado por no alcanzarse el estándar necesario para condenar. A favor de dicha posibilidad, véase HorviTz (2004) Tomo II, pp. 527-528; Correa y Reyes (2012) pp. 130-132; Mera (2002) p. 255. En contra, Falcone (2005) pp. 363-378; Miranda et al. (2012) pp. 369-381; Salas (2015) pp. 267-271.
} 
este procedimiento, pudiendo promoverse desde la formalización de la investigación. Si ni siquiera es imprescindible que la investigación esté agotada para que se adopte la decisión final, la deficiente calidad de la verdad procesal en que se funda es todavía más evidente ${ }^{77}$.

\section{MERMa DE LA EFICACIA PREVENTIVA DE LA PENA}

En cuanto a la crítica que apunta a la merma de la eficacia preventiva de la pena y de la función protectora de bienes jurídicos del derecho penal cuando se utilizan mecanismos de justicia penal negociada, por la imposición de una pena de entidad menor que la necesaria para desplegar su efecto preventivo general y especial, cabría efectuar un distingo. Si para la disminución de la pena no se redujeran artificiosamente los hechos atribuidos al imputado ni se alterara su calificación jurídica, en principio, no resultaría posible sostener la crítica, ya que en tal evento, a pesar de la menor cuantía de la pena, su efecto preventivo se mantendría igualmente dentro de los parámetros de lo que la ley considera adecuado. Pero si la rebaja de pena obedeciera a un apartamiento de la legalidad penal en la modulación de los hechos o en la invocación de su calificación jurídica, la crítica sí se mantendría, ya que el efecto preventivo de la sanción no alcanzaría el mínimo de lo que la ley estima necesario para los hechos realmente ejecutados.

Como puede advertirse, en este último caso nos encontraríamos frente a una situación exactamente inversa a la que más arriba identificamos como overcharging y que bien cabría designar como undercharging, esto es, la reducción artificial de los cargos contra el imputado para incentivarlo a renunciar al juicio, con la promesa de una pena inferior a la legalmente correspondiente al hecho que realizó.

En el caso del procedimiento abreviado y en el de la admisión de responsabilidad en el procedimiento simplificado, un sector de la doctrina ha denunciado la existencia de ciertas prácticas inadecuadas que pueden ser consideradas como manifestaciones de undercharging. Se han detectado manipulaciones del hecho punible para permitir una calificación jurídica menos grave ${ }^{78}$, modificaciones de la calificación jurídica del hecho para permitir una condena por un hecho distinto ${ }^{79}$, degradaciones de la calificación jurídica invocada sin ajustar el hecho imputado ${ }^{80}$, alegaciones de hechos atenuantes inexistentes y omisiones de hechos agravantes existentes ${ }^{81}$. En todos estos casos, no solo se ha desatendido el efecto preventivo de la pena que correspondería imponer a los hechos realmente ejecutados, sino que, además, se ha infringido el principio de objetividad del Ministerio Público, la legalidad penal sustantiva y algunas garantías procesales, como la estricta jurisdiccionalidad,

\footnotetext{
77 Véase NúNEz (2014) p. 393, quien destaca esta idea en relación con cualquier mecanismo de justicia penal negociada, al señalar que es necesario "poner atención en el hecho de que al producirse la negociación en el momento inicial del caso, el conocimiento sobre este y las pruebas son fragmentarias”.

78 Entre otras sentencias, puede verse CONTRA R.O.V.R. (2006).

79 Véase Contra M.D.M.C. (2003).

80 Entre otros fallos, puede verse CONTRA J.G.P.N. (2006).

81 Véase Contra B.A.S.S. (2007).
} 
infracciones ante las cuales, según ese mismo sector doctrinal, la actitud de los tribunales (juzgados de garantía), en general, ha sido un tanto complaciente ${ }^{82}$.

Estas prácticas han preocupado al Fiscal Nacional del Ministerio Público, quien ha instruido a los fiscales del país en el sentido de ceñirse estrictamente al principio de legalidad y atenerse al mérito de la investigación para determinar la procedencia de estos mecanismos de renuncia al juicio oral (Oficio de la Fiscalía Nacional N²86/2010, de 31 de mayo de 2010) $)^{83-84}$.

Nótese la incidencia que en este tema tiene el efecto penológico que la ley atribuye a la decisión del imputado de renunciar al juicio oral y someterse al mecanismo de justicia penal negociada. Aparentemente, cuando dicho efecto consiste en una rebaja de poca entidad en la sanción imponible, aumenta el riesgo de que tengan lugar situaciones de undercharging, con la finalidad de ofrecer al imputado un estímulo penológico más intenso que le lleve a aceptar aquella renuncia ${ }^{85}$.

En el caso del procedimiento monitorio, en cambio, no se ha tenido noticia de la ocurrencia de esta clase de situaciones. Dada la escasa gravedad de los delitos que se someten a él y la naturaleza de la pena pedida por el fiscal, aparentemente no hay grandes motivos para que se produzcan hipótesis de undercharging. Piénsese que, atendida la sanción prevista en la ley para estos delitos, bien podría aplicarse a su respecto el principio de oportunidad (art. 170 CPP).

\section{IGUALDAD ANTE LA LEY}

Por último, en cuanto a la vulneración que la aplicación de los mecanismos chilenos de justicia penal negociada puede significar para el principio de igualdad, por la discrecionalidad del Ministerio Público para decidir negociar con un imputado y no con otro, a pesar de que ambos puedan hallarse en la misma situación, cabe reconocer que, al menos en el caso del procedimiento abreviado, dicho riesgo es real. El hecho de que para que este procedimiento tenga lugar sea necesario que el fiscal esté de acuerdo, que su procedencia no dependa de un parámetro objetivo, como la pena asignada por la ley al delito, sino del criterio subjetivo del fiscal al momento de solicitar la pena en su acusación ${ }^{86}$, y que la ley no obligue a este a expresar las razones por las cuales ofrece esta vía procedimental a un im-

82 Del Río (2009) pp. 77-138; Del Río (2008) pp. 167-169; Rodríguez y Pino (2015) pp. 1012-1018. Véase, con todo, Contra C.J.T.B. (2016), sentencia en la que se afirma que el Ministerio Público, para convencer al imputado de que admita responsabilidad en el procedimiento simplificado, no puede solicitar una pena inferior a la legal.

83 Cfr. Navarro (2017) p. 263.

84 Sin embargo, no se advierte en las instrucciones generales de la autoridad máxima del Ministerio Público la misma preocupación por evitar la situación inversa: el overcharging.

85 En este sentido, Rodríguez y Pino (2015) p. 1011: "Son estas cortapisas para retribuir adecuadamente la renuncia al juicio oral que efectúa el requerido o acusado, las que han llevado a que el MP sistemáticamente modifique sus requerimientos y acusaciones, así como las penas pretendidas, mucho más allá de la mera incorporación de la atenuante del artículo $11 \mathrm{~N}^{\circ} 9$ del CP al juego operativo de las normas de determinación de pena, incurriendo en diversas prácticas de cuestionable legalidad”.

86 Esto último llevó al Instituto Chileno de Derecho Procesal a criticar la propuesta de regulación del procedimiento abreviado en el proyecto de Código Procesal Penal. Cfr. Facultad de Derecho (2003) p. 219. 
putado y no a otro, ni someta a control judicial su decisión de no ofrecerla en un caso concreto, hacen que el mencionado peligro no sea despreciable ${ }^{87}$. No obstante, a juicio del Tribunal Constitucional, dicho riesgo no justifica formular reproches de inconstitucionalidad, en la medida que se asuma que esta facultad discrecional del Ministerio Público no debe ser ejercida en forma arbitraria o caprichosa ${ }^{88}$. Eventualmente, para eliminar este riesgo, se podría estudiar la posibilidad de modificar la regulación de este procedimiento, haciendo depender la supresión del juicio oral, exclusivamente, de la voluntad del imputado, de un modo similar a lo que hoy sucede con el giudizio abbreviato italiano ${ }^{89}$.

La situación es distinta en el procedimiento simplificado con admisión de responsabilidad. Ello es así, porque en este procedimiento es la ley la que establece, como trámite obligatorio, la formulación de una pregunta del tribunal al imputado, en el sentido de si admite responsabilidad en los hechos contenidos en el requerimiento (art. 395 inc. $1^{\circ}$ CPP). No queda entregada a la discrecionalidad del fiscal la posibilidad del imputado de renunciar al juicio, admitiendo responsabilidad. Pero como este procedimiento no tiene lugar cuando el Ministerio Público pide una pena que excede de presidio o reclusión menor en su grado mínimo (art. $388 \mathrm{CPP})^{90}$, si el fiscal requiriere una pena superior, la única posibilidad del imputado de renunciar al juicio conforme a algún mecanismo de justicia penal negociada será el procedimiento abreviado, para promover el cual, como se ha dicho, se necesita la voluntad del fiscal, por lo que el denunciado peligro para la igualdad ante la ley no desaparece ${ }^{91}$.

También es diferente la situación en el procedimiento monitorio, ya que, en este, la decisión del imputado de renunciar al juicio, no reclamando contra la resolución que acoge el requerimiento y la proposición de imposición de una multa dentro de los quince días siguientes a la notificación de dicha resolución, no depende de la discrecionalidad del fiscal.

\section{CONCLUSIONES}

En este trabajo, después de revisar los principales defectos y virtudes atribuidos a los sistemas de justicia penal negociada, se ha examinado su aplicabilidad o inaplicabilidad a los mecanismos chilenos de justicia criminal negociada. El examen no permite efectuar una única valoración crítica.

En lo que respecta a las consideraciones de eficiencia en el funcionamiento del sistema, el procedimiento monitorio ha tenido una incidencia muy significativa, a diferencia

\footnotetext{
87 Advierte este riesgo para la igualdad ante la ley, PeCCHi (2005) p. 133.

88 Artículo 406, inciso final, Código Procesal Penal, STC rol N 1481-09.

89 Similar, Del Río (2009) p. 76, n. 84; pp. 193-195.

90 Destaca que el mínimo de pena privativa de libertad que debe pedir el fiscal para que tenga lugar el procedimiento abreviado es quinientos cuarenta y un días de presidio o reclusión menores en su grado medio, FARREN (2008) p. 695.

91 Véase Del Río (2009) p. 147, reconociendo esta discrecionalidad del fiscal: "En este supuesto, la Ley está autorizando a que el MP, ante un hecho que reviste caracteres de delito y que posea unos márgenes legales de pena desde presidio o reclusión menor en su grado mínimo y que se extiende a grados de penas superiores, pueda decidir someterlo a las reglas del 'procedimiento ordinario', pidiendo los tramos superiores de pena, o someterlo al 'procedimiento simplificado' -el procedimiento alternativo al ordinario-, al pedir la pena menor”.
} 
del procedimiento abreviado. También ha tenido gran incidencia el procedimiento simplificado, a pesar de no haber sido posible dimensionar con certeza su actual importancia como mecanismo de justicia negociada. Con todo, un análisis global de estos tres mecanismos sí permite efectuar una valoración positiva.

En cuanto a la incidencia de los mecanismos chilenos de justicia penal negociada en el respeto del derecho a ser juzgado en un plazo razonable, el examen de las estadísticas disponibles sobre duración de la tramitación de las causas penales permite (solo) intuir una incidencia real.

En relación con el carácter potencialmente coactivo de estos mecanismos, en el caso del procedimiento abreviado, la exigencia legal de que el imputado acepte los hechos de la acusación constituye un riesgo de coacción. Dicho riesgo aumentó con la Ley $\mathrm{N}^{\circ}$ 20.074, al prever la posibilidad de considerar tal aceptación como base para la atenuante del artículo $11 \mathrm{~N}^{\circ} 9 \mathrm{CP}$, y se incrementó considerablemente con la Ley $\mathrm{N}^{\circ} 20.931$, al establecer la posibilidad de rebajar la pena en un grado, tratándose de ciertos delitos contra la propiedad de frecuente comisión, modificaciones que ampliaron la diferencia entre la pena susceptible de imponerse en el procedimiento abreviado y la eventualmente aplicable en el juicio oral, mermando la libertad del imputado en su decisión de renunciar al juicio.

También en el procedimiento simplificado hay un riesgo de coacción, atendidas la exigencia legal de que el imputado admita responsabilidad para poder renunciar al juicio, y la posibilidad de rebajar la pena en un grado cuando se trata de esos mismos delitos contra la propiedad, así como, mediante analogía, la posibilidad de aplicar la atenuante del artículo $11 \mathrm{~N}^{\circ} 9 \mathrm{CP}$. Pero en este procedimiento, la diferencia entre la pena imponible si se admite responsabilidad y la aplicable en juicio no es muy grande, lo que permite moderar mucho la crítica.

Con mayor claridad todavía, en el procedimiento monitorio, el hecho de que el imputado arriesga una multa de baja cuantía, no permite afirmar que la posible rebaja del 25 $\%$ de su monto sirva de base para atribuirle un carácter coactivo.

En lo que respecta a la crítica relativa a la deficitaria verdad procesal que se alcanzaría con los mecanismos chilenos de justicia penal negociada, no puede sino reconocerse su validez. El hecho de que en estos casos la sentencia no se funde en prueba rendida en juicio oral, resalta su carácter contra epistemológico. Se trata de un costo que debe ser aceptado por cualquier sistema de justicia criminal negociada. Al menos, en el caso chileno, la condena no puede fundarse solamente en el acuerdo (arts. 340 inc. $3^{\circ}$ y 412 inc. $2^{\circ} \mathrm{CPP}$ ). Si pudiera basarse exclusivamente en este, la verdad procesal en que se funda la sentencia sería todavía más deficiente.

En todo caso, tratándose del procedimiento monitorio y del procedimiento simplificado con admisión de responsabilidad, la baja gravedad de los delitos de que se trata permite considerar tolerable la deficiente calidad de la verdad procesal que se alcanza. En cambio, en el procedimiento abreviado, dicho déficit se torna inaceptable, especialmente cuando se trata de ciertos delitos contra la propiedad, para los cuales puede imponerse una pena privativa de libertad de hasta diez años, aun cuando la investigación no esté agotada.

En cuanto a la crítica relativa a la merma de la eficacia preventiva de la pena que los mecanismos chilenos de justicia penal negociada podrían producir, en la práctica, en proce- 
dimientos abreviados y en admisiones de responsabilidad en procedimientos simplificados, se han detectado lamentables casos de undercharging, en los que la crítica ha resultado plenamente justificada. No se ha tenido noticia de estas prácticas en el procedimiento monitorio.

Finalmente, en relación con la posible afectación del principio de igualdad, en el caso del procedimiento abreviado, el riesgo de que ello ocurra es real, ya que la promoción de este mecanismo de justicia penal negociada queda entregada exclusivamente a la discrecionalidad del fiscal. Distinta es la situación en la admisión de responsabilidad en el procedimiento simplificado, y en el procedimiento monitorio.

\section{BIBLIOGRAFÍA CITADA}

Alschuler, Albert W. (1979): "Plea bargaining and its history", Columbia Law Review, vol. 79, $\mathrm{N}^{\circ} 1$ : pp. 1-43.

Alschuler, Albert W. (1975): “The defense attorney's role in plea bargaining”, The Yale Law Journal, vol. 84, N 6: pp. 1179-1314.

Altenhain, Karsten; Dietmeier, Frank; May, Markus (2013): Die Praxis der Absprachen in Strafverfahren (Baden-Baden, Nomos).

ANDrÉs IbÁÑEZ, Perfecto (2003) "Sobre el valor de la inmediación (Una aproximación crítica)", Jueces para la democracia, $\mathrm{N}^{\circ}$ 46: pp. 57-66.

Arellano Quintana, Jaime (dir.) (2017): Desafíos de la Reforma Procesal Penal en Chile: Análisis retrospectivo a más de una década (Santiago, CEJA-JSCA).

Armenta Deu, Teresa (2014): "Proceso abreviado, juicio rápido y prisión provisional", La Misma, Estudios de Justicia Penal (Madrid, Marcial Pons) pp. 271-292.

Barona Vilar, Silvia (2004): Seguridad, celeridad y justicia penal (Valencia, Tirant lo Blanch).

Baytelman Aronowsky, Andrés (2000), "El juicio oral”, en AA.VV., Nuevo proceso penal (Santiago, Conosur) pp. 227-281.

Baytelman Aronowsky, Andrés; Duce Julio, Mauricio (2004): Litigación penal. Juicio oral y prueba (Santiago, Ediciones Universidad Diego Portales).

Binder, Alberto M. (2004): Introducción al Derecho procesal penal (Buenos Aires, Ad-Hoc, segunda edición).

Bovino, Alberto (2001): "Procedimiento abreviado y juicio por jurados", en MaIER, Julio B. J.; Bovino, Alberto (comps.), El procedimiento abreviado (Buenos Aires, Editores del Puerto).

Cerda San Martín, Rodrigo (2010): Manual del sistema de justicia penal, Tomo II (Santiago, Librotecnia, segunda edición).

Chahuán Sarrás, Sabas (2012): Manual del nuevo procedimiento penal (Santiago, Abeledo Perrot, LegalPublishing, Thomson Reuters, séptima edición).

Cociña Cholaky, Martina (2012): La verdad como finalidad del proceso penal (Santiago, Abeledo Perrot, LegalPublishing, Thomson Reuters).

Córdoba, Gabriela E. (2001): “Acuerdos informales en el procedimiento penal alemán”, en AA.VV., Nuevas formulaciones en las ciencias penales. Homenaje al profesor Claus Roxin (Córdoba, Marcos Lerner Editora Córdoba, La Lectura Libros Jurídicos). 
Correa Robles, Carlos; Reyes López, Mauricio (2012): El procedimiento abreviado y la justicia criminal negociada. Derecho chileno y comparado (Santiago, Editorial Jurídica de Chile).

Correa Urmeneta, Tomás (2017): Algunos problemas del procedimiento abreviado, Trabajo de memoria, Pontificia Universidad Católica de Valparaíso.

De Diego Díez, Luis Alfredo (1999): Justicia criminal consensuada (Algunos modelos del derecho comparado en los EE.UU., Italia y Portugal) (Valencia, Tirant lo Blanch).

Del Corral, Diego (2010): Juicio abreviado (Buenos Aires, Astrea).

Del Río Ferretti, Carlos (2010): “Dos formas discutibles de poner en duda el carácter cognoscitivo de la aplicación judicial del Derecho penal: el principio del consenso y la garantía de la no agravación punitiva", Revista de Derecho de la Pontificia Universidad Católica de Valparaíso, vol. XXXIV: pp. 349-383.

Del Río Ferretti, Carlos (2009): Proceso penal, consenso de las partes y enjuiciamiento jurisdiccional (Santiago, Librotecnia).

Del Río Ferretti, Carlos (2008): "El principio del consenso de las partes en el proceso penal y enjuiciamiento jurisdiccional: aclaraciones conceptuales necesarias", Revista Chilena de Derecho, vol. 35, º 1: pp. 157-182.

Devers, Lindsey (2011): Plea and Charge Bargaining. Research Summary (Arlington, Bureau of Justice Assistance, U.S. Department of Justice).

Duce Julio, Mauricio (2013): “¿Debiéramos preocuparnos de la condena de inocentes en Chile? Antecedentes comparados y locales para el debate", Revista Ius et Praxis, año 19, $\mathrm{N}^{\circ}$ 1: pp. 77-138.

Duce Julio, Mauricio (2011): “Diez años de reforma procesal penal en Chile: apuntes sobre su desarrollo, logros y objetivos", en Fuentes Maureira, Claudio (coord.), Diez años de la reforma procesal penal en Chile (Santiago, Ediciones Universidad Diego Portales) pp. 191-234.

Duce Julio, Mauricio; Marín Verdugo, Felipe; Riego Ramírez, Cristián (2008): "Reforma a los procesos civiles orales: consideraciones desde el debido proceso y calidad de la información", en CABEZÓN, A. (coord.), Justicia civil: Perspectivas para una reforma en América Latina (Santiago, CEJA) pp. 13-94.

Durán Sanhueza, Rafael (2009): Procedimiento simplificado y monitorio en el Código Procesal Penal chileno (Santiago, Librotecnia).

Facultad de Derecho. Universidad de Chile (2003): Reforma Procesal Penal. Génesis, historia sistematizada y concordancias, Tomo III (Santiago, Editorial Jurídica de Chile).

Falcone Salas, Diego (2005): "La absolución en el procedimiento abreviado", Revista de Derecho de la Pontificia Universidad Católica de Valparaiso, vol. XXVI: pp. 363-378.

Farren Cornejo, Fernando (2008): "Procedimientos simplificado y abreviado en la actualidad”, en Rodríguez Collao, Luis (coord.), Delito, pena y proceso. Libro homenaje a la memoria del profesor Tito Solari Peralta (Santiago, Editorial Jurídica de Chile) pp. 679-697.

Ferrajoli, Luigi (2000): Derecho y razón. Teoría del garantismo penal (trad. Perfecto Andrés Ibáñez, Alfonso Ruiz Miguel, Juan Carlos Bayón Mohino, Juan Terradillos Basoco y Rocío Cantarero Bandrés, Madrid, Trotta, cuarta edición). 
García Torres, María José (2004): El proceso penal abreviado y el acuerdo del imputado. Legislación comparada y análisis constitucional (Buenos Aires, Fabián. J. Di Plácido Editor).

Gascón Abellán, Marina (1999): Los hechos en el derecho. Bases argumentales de la prueba (Madrid-Barcelona, Marcial Pons).

Gimeno Sendra, Vicente (2012): Derecho Procesal Penal (Navarra, Civitas, Thomson Reuters, Aranzadi).

Gössel, Karl Heinz (2007): "Acerca del acuerdo en el proceso penal”, en El Mismo, El Derecho Procesal Penal en el Estado de Derecho. Obras completas, Tomo I (Buenos Aires, Rubinzal-Culzoni Editores) pp. 277-293

GuZmán, Nicolás (2001): "La verdad y el procedimiento abreviado", en Maier, Julio B. J.; Bovino, Alberto (comps.), El procedimiento abreviado (Buenos Aires, Editores del Puerto) pp. 277-298.

GuZmán Dalbora, José Luis (2008): "Involución de la reforma procesal penal chilena", Revista Procesal Penal, Nº8: pp. 9-19.

Herrera Guerrero, Mercedes (2016): "La negociación en el proceso penal desde la dogmática del Derecho penal. Especial referencia a los ordenamientos español y peruano", Politica Criminal, vol. 11, No 21: pp. 229-263.

Herrera Guerrero, Mercedes (2014): La negociación en el nuevo proceso penal. Un análisis comparado (Lima, Palestra Editores).

Hidalgo Arancibia, Mauricio (2004): "Propuestas para perfeccionar las normas y aplicación del procedimiento simplificado en el proceso penal”, Revista Procesal Penal, $\mathrm{N}^{\circ} 24$ : pp. 11-22.

Horvitz Lennon, María Inés (2016): "Efectos reflejos de la sentencia penal condenatoria y su incidencia en los juicios civiles", Revista de Derecho del Consejo de Defensa del Estado, $\mathrm{N}^{\circ}$ 35: pp. 41-70.

Horvitz Lennon, María Inés (2004): en Horvitz Lennon, María Inés; López Masle, Julián, Derecho Procesal Penal Chileno, Tomo II (Santiago, Editorial Jurídica de Chile).

Horvitz Lennon, María Inés (1994): "Algunas formas de acuerdo o negociación en el proceso penal: tendencias del derecho comparado", Revista de Ciencias Penales, tomo XL, $\mathrm{N}^{\circ}$ 2: pp. 27-40.

Langbein, John H. (1978): "Torture and Plea Bargaining", The University of Chicago Law Review, vol. 46, $\mathrm{N}^{\circ} 1$ : pp. 3-22.

LANGER, Máximo (2010): "From legal transplants to legal translations: the globalization of plea bargaining and the americanization thesis in criminal procedure", en THAMAN, Stephen C. (ed.), World Plea Bargaining. Consensual procedures and the avoidance of the full criminal trial (Durham, North Carolina, Carolina Academic Press) pp. 3-80.

Libedinsky Ventura, Sofía (2001): "Negociación y salidas alternativas", en AA.VV., Seminario Reforma Procesal Penal. Universidad Católica de Temuco (Santiago, Conosur LexisNexis) pp. 145-156.

LIPPKE, Richard L. (2011): The ethics of plea bargaining (New York, Oxford University Press). LOCKER, Tobias (2015): Absprachen im Strafverfahren. Ein Überblick und alternative Verfahrensweisen (Hamburg, Diplomica Verlag). 
López Masle, Julián (2002): en Horvitz Lennon, María Inés; López Masle, Julián, Derecho Procesal Penal Chileno, Tomo I (Santiago, Editorial Jurídica de Chile).

Maier, Julio B. J. (2001): "Prólogo", en Maier, Julio B. J.; Bovino, Alberto (comps.), El procedimiento abreviado (Buenos Aires, Editores del Puerto) pp. I-III.

Mallord, Joel (2014): "Putting plea bargaining on the record", University of Pennsylvania Law Review, vol. 162: pp. 683-718.

Marino Aguirre, Santiago (2001): El juicio penal abreviado (Buenos Aires, Abeledo-Perrot).

Martínez, Santiago (2004): La víctima y el juicio abreviado (Buenos Aires, Fabián J. Di Plácido Editor).

Maturana Miquel, Cristián y Montero López, Raúl (2017): Derecho Procesal Penal, Tomo II (Santiago, Librotecnia, tercera edición).

Matus Acuña, Jean Pierre (2011): "La justicia penal consensuada en el nuevo Código de Derecho Procesal Penal", en El Mismo, Derecho penal, criminología y política criminal en el cambio de siglo (Santiago, Editorial Jurídica de Chile) pp. 53-80.

Mera Figueroa, Jorge (2002): “Discrecionalidad del Ministerio Público, calificación jurídica y control judicial", Informes de investigación, Centro de Investigaciones Jurídicas, Facultad de Derecho Universidad Diego Portales, N 12, año 4: pp. 235-258.

Miranda Estrampes, Manuel; Cerda San Martín, Rodrigo; Hermosilla Iriarte, Francisco (2012): Práctica de la prueba en el juicio oral. Su valoración y el estándar del "más allá de toda duda razonable" (Santiago, Librotecnia).

Navarro Dolmestch, Roberto (2017): Criterios de actuación juridica del Ministerio Público. Análisis dogmático y compendio (Santiago, Librotecnia).

Nieva Fenoll, Jordi (2012): Fundamentos de Derecho procesal penal (Montevideo, B de F).

Nieva Fenoll, Jordi (2010): "Los problemas de la oralidad”, Revista do Ministério Público do RS, Porto Alegre, $\mathrm{N}^{\circ}$ 67: pp. 237-257.

Núñez Ojeda, Raúl (2014): Código Procesal Penal (Santiago, LegalPublishing - Thomson Reuters, tercera edición).

Palomo Vélez, Diego (2010): Reforma procesal civil. Oralidad y poderes del juez (Santiago, Abeledo Perrot, Legal Publishing).

Pecchi Croce, Carlos (2005): "El procedimiento abreviado en el nuevo Código Procesal Penal”, Revista Actualidad Jurídica, No 11: pp. 119-137.

Pecchi Croce, Carlos / Ortiz Sepúlveda, Eleodoro (2003): "Análisis estadístico de los mecanismos de descongestión del juicio oral en el nuevo proceso penal”, Revista Actualidad Jurídica, $\mathrm{N}^{\circ}$ 7: pp. 47-59.

PizzI, William T. (1999): Trials without truth. Why our system of criminal trials has become an expensive failure and what we need to do to rebuild it (New York, New York University Press).

Riego Ramírez, Cristián (2017): "El procedimiento abreviado en la ley 20.931”, Política Criminal, vol. 12, No 24: pp. 1085-1105.

Riego Ramírez, Cristian (2001): "El procedimiento abreviado en Chile", en Maier, Julio B. J.; Bovino, Alberto (comps.), El procedimiento abreviado (Buenos Aires, Editores del Puerto) pp. 453-475. 
Riego Ramírez, Cristián (2000): “El procedimiento abreviado", en AA.VV., Nuevo proceso penal (Santiago, Conosur) pp. 205-226.

Ritter, Andrés (2003): "Informe de una visita”, en Hernández Basualto, Héctor (ed.), Evaluación de la Reforma Procesal Penal chilena desde la perspectiva del sistema alemán (Santiago, Sociedad Alemana de Cooperación Técnica, GTZ) pp. 20-76.

Rodríguez García, Nicolás (1997): La justicia penal negociada. Experiencias de derecho comparado (Salamanca, Ediciones Universidad de Salamanca).

Rodríguez Vega, Manuel (2011): "Discrecionalidad del Ministerio Público y objeto del juicio abreviado", Revista de Derecho de la Pontificia Universidad Católica de Valparaiso, vol. XXXVI: pp. 495-529.

Rodríguez Vega, Manuel; Pino Reyes, Octavio (2015): “El principio de obligatoriedad en el ejercicio de la acción penal en los procedimientos jurisdiccionales basados en la autoincriminación", Revista Chilena de Derecho, vol. 42, N 3: pp. 1003-1033.

Rönnau, Thomas (1990): Die Absprache im Strafproze $\beta$ (Baden-Baden, Nomos Verlag).

Salas Astrain, Jaime (2015): Problemas del proceso penal. Investigación, etapa intermedia y procedimientos especiales (Santiago, Librotecnia, segunda edición).

Schünemann, Bernd (2005): La reforma del proceso penal (trad. Mariana Sacher, Madrid, Dykinson).

SCHÜNEMANN, Bernd (2002): “¿Crisis del procedimiento penal? (¿Marcha triunfal del procedimiento penal americano en el mundo?)”, en El Mismo, Temas actuales y permanentes del Derecho penal después del milenio (trad. Silvina Bacigalupo, Madrid, Tecnos) pp. 288-302.

Silva Sánchez, Jesús María (2015): “Acuerdos: ¿Proceso sin Derecho?”, en El Mismo, En busca del Derecho penal. Esbozos de una teoría realista del delito y de la pena (Montevideo, Buenos Aires, B de F): pp. 283-285.

TscherWInkA, Ralf (1995): Absprachen im Strafproze $\beta$ (Frankfurt am Main, Peter Lang).

Turner, Jenia I. (2016): "Plea bargaining and disclosure in Germany and the United States: comparative lessons", William and Mary Law Review, vol. 57: pp. 1549-1596.

Villar, Ariel H. (1997): El juicio abreviado (Buenos Aires, Némesis).

Volk, Klaus (2016): Curso fundamental de Derecho procesal penal (trad. Alberto Nanzer, Noelia T. Núñez, Daniel R. Pastor y Eugenio Sarrabayrouse, Buenos Aires, Hammurabi).

WILKINS, William W. Jr. (1988): "Plea negotiations, acceptance of responsability, role of the offender, and departures: Policy decisions in the promulgation of Federal Sentencing Guidelines", Wake Forest Law Review, vol. 23, N 2: pp. 181-202.

\section{JURISPRUDENCIA CITADA}

Contra C.J.T.B. (2016): Corte de Apelaciones de Valparaíso, 24 de octubre de 2016 (recurso de nulidad en procedimiento simplificado con admisión de responsabilidad).

Contra O.G.S.M. (2015): Corte de Apelaciones de Concepción, 31 de julio de 2015 (recurso de nulidad en procedimiento simplificado con admisión de responsabilidad).

Contra B.A.S.S. (2007): Juzgado de Garantía de Santiago (14º), 20 de marzo de 2007 (procedimiento abreviado). 
Contra R.O.V.R. (2006): Juzgado de Garantía de Santiago (14º), 29 de noviembre de 2006 (procedimiento abreviado).

ContRa J.G.P.N. (2006): Juzgado de Garantía de Santiago ( $\left.8^{\circ}\right)$, 8 de septiembre de 2006 (procedimiento abreviado).

Contra M.D.M.C. (2003): Juzgado de Garantía de Linares, 23 de febrero de 2003 (procedimiento abreviado).

REQUERIMIENTO DE INAPLICABILIDAD POR INCONSTITUCIONALIDAD PRESENTADO POR JESÚs MANzur Saca respecto del inciso final del artículo 406 del Código Procesal Penal en Causa RUC Nº 0800123624-6, del Tercer Juzgado de Garantía de Santiago: Tribunal Constitucional chileno, Rol No 1481-09, 10 de mayo de 2011. 
